\title{
Model for Choosing Best Alternative to Remove Space Junk
}

\section{Fei Zheng}

\author{
Department of North China Electric Power University（Baoding）, Baoding 071000, China \\ 18331125631@163.com
}

Keywords: Space debris, entropy weight

\begin{abstract}
NASA demonstrated that there are more than 500,000 pieces of space debris around the earth.It is necessary to remove the space junk because they do great harm to the aircraft. How to remove the space junk has become a universal concern.. In this paper, model is established to find the best alternative to remove the space junk.

Fuzzy preference decision time-dependent model based on entropy weight and ameliorative AHP are applied to determine the best alternative or combination of alternatives that a private firm could adopt as a commercial opportunity to address the space debris problem. We analyze and calculate the costs, risks, equipment life, the number of space junk which can be cleared and profit operation of space elevator, small satellites, applications of current and magnetic and laser broom to get a best method.

Finally, we analyze the relationship between orbit altitude and generality of collision.It is shown that the proposed models are feasible and reliable.
\end{abstract}

\section{Introduction}

On October 4, 1957, the first artificial earth satellite Sputnik 1 was launched into orbit, which expanded the human activity to the vast cosmic space. With the rapid development of the space technology, world's economy and social progress, a large number of man-made objects have been launched to explore the outer space. In addition to micrometeoroid, there are more than 500,000 pieces of space debris around the earth. The space debris could affect the safety of man-made objects. On February 11, 2009, Russian satellite Kosmos-2251 collided with US satellite Iridium-33. So the space debris has attracted international attention.

General space debris includes micrometeoroid and the man-made debris. Micrometeoroid is in the orbit of the solar system. It has high speed, complex composition but away from the Earth's orbit .So the current of human space exploration is not significantly affected by this.

Man-made debris, mostly refers to the abandoned spacecraft and human fragments produced by explosion or collision, which has a wide range from paint to the abandoned satellite and is in a high speed. Distribution of man-made debris covers commonly used near-earth orbit and geosynchronous, where the former is more aggressive. Due to the increasing number of space debris, orbital area is becoming increasingly crowded.

As we are asked, we need to build a model to determine best alternative to remove space junk

\section{Assumptions}

Before analyzing the presented models, we make some reasonable assumptions as follows:

- The determination of business opportunity is analyzed based on the following factors: demand, the appreciation of space, cost, national policy, competitiveness and risk.

- The feasibility degree is only determined by service life, benefit, risks, costs and collective volume.

- The benefit of removing a fixed amount of space junk is constant with different methods. 


\section{Establish the Mathematical Model}

Use Fuzzy Preference Decision Method Based on Entropy Weight and Ameliorative AHP to determine the best alternative or combination of alternatives that a private firm could adopt as a commercial opportunity to address the space debris problem.

Meanwhile, time is the basis for the formation of the economic benefits and the length of time in economic activity significantly affect economic height.The more time is spentin economic activity, the more economic benefits we will get.On the contrary, the less time is spentin economic activity, the less economic benefits we will get.Assuming that the economic activities of all programs have same time so the establishment of the model is based on the time.

We can analyze and calculate the costs, risks, equipment life, the number of space junk which can be cleared and profit operation of space elevator, small satellites, applications of current and magnetic and laser broom to get a best method .

Assuming that we can get same profit by clearing the same amount of garbage these different methods and taking into account other factors, We can assume a profit.

Get a qualitative analysis of risks, equipment life, the number of space junk which can be cleared .

Table 1 A qualitative analysis of risks, equipment life, the number of space junk

\begin{tabular}{c|ccc}
\hline & risk & equipment life & $\begin{array}{c}\text { the number of } \\
\text { space junk }\end{array}$ \\
\hline $\begin{array}{c}\text { Space elevator } \\
\text { Small satellites }\end{array}$ & higher & general & general \\
higher & general & high \\
$\begin{array}{c}\text { andications of current } \\
\text { Lagnetic }\end{array}$ & higher & higher & high \\
Laser broom & high & higher & general \\
\hline
\end{tabular}

Make the above qualitative indicators into quantitative indicators by Bipolar ratio method, and combined with other quantitative indicators to have the following table.

Table 2 Quantitative indicators

\begin{tabular}{c|ccccc}
\hline & Rosts (hundred \\
million dollars) & Risk & Equipment life & $\begin{array}{c}\text { The } \\
\text { number of } \\
\text { space junk }\end{array}$ & $\begin{array}{c}\text { Profit } \\
\text { hundred } \\
\text { million } \\
\text { dollars }\end{array}$ \\
\hline $\begin{array}{c}\text { Space elevator } \\
\text { Small satellites }\end{array}$ & 2.4 & 1 & 5 & 5 & 2.6 \\
$\begin{array}{c}\text { Applications of } \\
\text { current and } \\
\text { magnetic }\end{array}$ & 0.05 & 1 & 5 & 7 & 6 \\
Laser broom & 2 & 3 & 9 & 7 & 6.95 \\
\hline
\end{tabular}

We make all attributes indicators go through normalization processing by Range transformation to have the following matrix

Then,establish judgment matrix C.Due[6] to a different focus when judging there are many different matrix C.Here we focus on several different judgment matrix $\mathrm{C}$ to calculate the results, and get conclusion.

\section{Conclusions}

(1) If the costs is as important as risks, more important than equipment life, and as important as the number of space junk and not as important as profit , risks is as important as equipment life, more important than the number of space junk and not as important as profit, equipment life is as important as the number of space junk and not as important as profit and the number of space junk is not as 
important as profit. We have the following table.

Table $3 \mathrm{C} 1$ information table

\begin{tabular}{c|ccccc}
\hline C1 & Cost & Risk & Equipment life $\begin{array}{c}\text { The } \\
\text { number } \\
\text { of space } \\
\text { junk }\end{array}$ & Profit \\
\hline Cost & 0 & 0 & 1 & 0 & -1 \\
Risk & 0 & 0 & 0 & 1 & -1 \\
$\begin{array}{c}\text { Equipment life } \\
\text { The number of } \\
\text { space junk }\end{array}$ & -1 & 0 & 0 & 0 & 1 \\
Profit & 1 & -1 & 0 & 0 & -1 \\
\hline
\end{tabular}

According to this judgment matrix, by using MATLAB to solve the resulting get relative membership degree vector $U=[0.1210,0.455,0.9445,0.3293]$.According to this vector we can know that applications of current and magnetic is the best method among these methods.[7]

(2) If the costs is as important as profit and more important than equipment life, the number of space junk and risk, risks as as important as the number of space junk, more important than equipment life and not as important as profit, equipment life is as important as the number of space junk and not as important as profit and the number of space junk is not as important as profit. We have the following table.

Table 4 C2 information table

\begin{tabular}{c|ccccc}
\hline \multirow{2}{*}{ C2 } & Cost & Risk & $\begin{array}{c}\text { Equipment } \\
\text { life }\end{array}$ & $\begin{array}{c}\text { The } \\
\text { number of } \\
\text { space junk }\end{array}$ & Profit \\
\hline Cost & 0 & 1 & 1 & 1 & 0 \\
Risk & -1 & 0 & 0 & 1 & -1 \\
$\begin{array}{c}\text { Equipment life } \\
\text { The number of } \\
\text { space junk }\end{array}$ & -1 & 0 & 0 & 0 & -1 \\
Profit & -1 & -1 & 0 & 0 & -1 \\
\hline
\end{tabular}

According to this judgment matrix, by using MATLAB to solve the resulting get relative membership degree vector $U=[0.0632,0.2397,0.9747,0.1466]$. According to this vector we can know that applications of current and magnetic is the best method among these methods.

On the base of the above,we can recognize the model can give the best alternatives if it gets enough information.

In summary, the model can be able to assess independent alternatives as well as combinations of alternatives .

\section{References}

[1] Sun Gang et al: evaluation of the orbital debris model of the European Space Agency 2000 fourth (total 65)

[2] Chen Dan: clean space road "stumbling block" [J] new science fiction (Abstract Edition) 2011 (6) 
[3] Si Shou Kui et al: Mathematical modeling algorithm and its application, National Defence Industry Press, chapter 8.

[4] Shen Jianming et al. Project risk management [M]. Beijing: Mechanical Industry Press,,2004( 6) [5] 1. Dept . of Math, Huanggang Normal University, Huangzhou 438000 , China ; 2.School of Sciences, WUT, Wuhan 430070 , China

[6] Xie Rong Where a minimum cost maximum flow algorithm of transportation network seek [J] Operations Research and Management, 2000, 9 (4): 33238.

[7] Jiang Qiyuan et al mathematical model [M] 2nd ed. Beijing: Higher Education Press, 2001.3052324 